\title{
Mirror, mirror on the wall, who in this land is fairest of all? Teaching reflection to novice students
}

\section{Lesley Cooper ${ }^{1}$}

Summary: This paper offers an approach to teaching novice students the concept of reflection and the ways it can be used in practice. The paper is presented in three parts each outlining ways of teaching novice students entering practice placements for the first time. It begins with discussion of a student centered approach to teaching, and then presents the concepts and description of images used to engage students in thinking about the complexity of practice and finally discussed the theoretical underpinnings of reflection in social work.

Keywords: Degree in Social Work; practice learning; practice teaching; quality assurance; social care governance; academic/agency partnership; preparation for practice; group learning; group supervision; models of practice learning.

1. Dean, Lyle S. Hallman Faculty of Social Work, Wilfred Laurier University

Address for Correspondence: Lyle S. Hallman Faculty of Social Work, Wilfred Laurier University, 120 Duke St W, Kitchener, Ontario N2H 3W8, Canada. lesleycooper@wlu.ca 


\section{Introduction}

In social work programs students are often asked to reflect on your experiences with a client. This request is followed by a comment such as the more specific you are the better. It is not immediately clear to novice students what is meant by the word reflection, what being specific refers to, or how one might go about this process to the satisfaction of the educator or practice teacher. If students experience uncertainty about why and how to reflect, so do many supervisors and lecturers who may have poorly conceptualized understandings of the term reflection. There is furthermore no or little consensus on when reflection has been achieved and whether is can be safely used as part of the assessment of professional training (Ixer, 1999).

For the past 11 years I have been responsible for coordinating field education in my university. From this position I have developed an understanding of motivations and pedagogical intentions of practice teachers and of the students' intellectual struggles. Practice teachers are aware of the value of reflection in increasing self-awareness, for developing empathy, for examining value assumptions and stereotypes and development of practice theory but many are not able to provide a clear explanation of reflection and its various nuances. They are not able to put their complex understandings into words. When students ask them what is this thing called reflection, many are not able to respond with simplicity. Students, in the absence of clarity resist demands to reflect on practice thereby creating unnecessary tensions in the learning relationships. As an educator responsible for preparing students for practice learning, I have found it necessary to assist novice students to learn the concept and process of reflection.

In this paper, I offer an approach to teaching novice students the concept of reflection and the ways in which it can be used in practice. These comments are based on my pedagogical struggles on educating students to become reflective practitioners. I want students to move from a situation where they see their practice as certain and predictable, to one of seeing it as greatly complex. This paper is presented in three parts each outlining approaches to teaching novice students entering their field education placements for the very first time. The paper discusses a student centered approach to teaching, presents the concepts and description of images used to engage students in thinking about the complexity of practice, and finally discusses the theoretical underpinnings of reflection in social work. 


\section{Starting where the student is}

For many year the concept of 'start where the client is' has been a professional canon. This principle is also important for teaching (Rogers, 1969). By the time students are ready to start their first placements, they have heard constant reference to 'reflection', 'critical reflection', 'reflective consideration of the situation', 'reflection-in-action' and 'reflection-on-action'. These references to reflection are rarely accompanied by conceptual or practical explanations, and are not clearly linked to personal or professional experiences. I am concerned that students may already see reflection as a fashion statement that has lost its meaning. I am also aware of the dangers in turning reflection into a technique or set of procedures that will be followed without deliberate consideration. Reflection is complex concept and process that cannot be readily reduced to a set of competencies for students to follow.

Howard Goldstein (2001) asked an important question: how does one learn to be a social worker? He answered this rhetorical question saying that learning is achieved by shifting from a teaching to a learning model. Reflection is an important part of the learning paradigm and is based on active involvement of students as part of a professional community in a process of discovery, problem solving, and linking of real experience with innovative and creative action strategies. Teachers can tell students in lectures and tutorials about reflection but this does not mean they understand the concept and can use it in their practice. Before students come to understand reflective practice, they have to be sufficiently uncomfortable, uncertain and ready for discovery. The timing of discussions about reflection and the pedagogical practices within the classroom is of great importance with the classroom providing a safe place for teaching of reflection (Graham and Megarry, 2005).

Students entering placements for the first time may experience elation but are also uncomfortable and have doubts about their ability. Many beginning students are not sophisticated thinkers. Initially they have a simplistic view of the world, dividing it into good and bad, right and wrong. They want simple answers. How should we do this thing called reflection? What steps and processes do we follow? How do we know if we have done it 'the right way'? These questions make the process of explaining the nuances and complexities of reflection a challenging teaching process.

24 Journal of Practice Teaching \& Learning 7(1) 2006-07, pp.22-38. (C 2007 Whiting \& Birch Ltd 


\section{Reflection and its presentation in teaching}

Reflection is a complex concept because it comes from various intellectual traditions in social work, education and critical theory. The educational concepts underpinning reflection are outlined in the final section of this paper but to assist the reader with the structure of the learning, the following description is provided. Reflection is an intentional professional activity. It can be used to analyse self, interactions with others, as well as the social context including societal structures and assumptions. These analyses can be used for problem solving and further development of practice theory. Reflection involves a process of discovery, development of a capacity to notice self, others and the milieu; and the mobilization of cognitive and creative skills. Learning how to be reflective means understanding the value of preparatory empathy, the triggers associated with learning and the value of an ignorance perspective.

Many of our students come to tertiary study with an understanding of multi-media that incorporates visual and rapid images through the internet, screen and television. For this reason, I use visual imagery as a way of explaining reflection. Gould (1996) referred to the importance of using imagery and creativity as an active aid to reflective learning. He noted how verbal and visual images have been used historically to convey complex ideas and models. In social work, Gould has researched the way in which students and practitioners use imagery to understand practice. In presenting the following concepts, visual images are used as the focal point to convey the complexity of the concept of reflection. These images are supplemented with verbal explanations.

\section{Discovery}

The standard dictionary understanding of reflection is misleading. A conventional dictionary definition refers to reflection as sending back an image. When we stand in front of a mirror and look, we see a very clear reflection of who we are. This reflection is also distorted as it is a mirror image but this is so common place that we ignore it. In seeing an image of ourselves, we do not see the full range of possibilities, merely a replication of an existing state of affairs. In reflecting on ourselves or our practice, we may be aware of some aspects of ourselves but also may

25 Journal of Practice Teaching \& Learning 7(1) 2006-07, pp.22-38. ( 2007 Whiting \& Birch Ltd 
be blind to particular aspects of our physical and emotional being. In discussing reflection in this way, the students realise that I expect them to start by describing an existing state of affairs, and then move beyond this to illuminate the unconscious and intentional activities.

Even the simplest reflection can be an important discovery for a beginner. The first time a young child discovers themselves in a mirror can bring the child both a sense of joy and discovery. Even at this early stage, a young child will begin the process of problem solving by looking behind the mirror and failing to make the anticipated finding of a baby. Learning has commenced.

\section{Noticing}

Boud and Walker (1990, p.67) referred to the importance of noticing - the act of becoming aware of what is happening in and around oneself. Noticing involves awareness of the milieu in which the learner finds themselves, as well as the personal, cognitive and behavioural factors such as how they are thinking, feeling and intervening. Reflecting involves becoming aware of the milieu and what is happening around, to and with them. It entails being aware of what they are doing and thinking, and how this is influencing others. It also means being aware of what they are feeling and valuing as emotional responses that are critical to understanding social work practice.

The image of a mooring in the Moselle River, Germany is chosen as an example of noticing and a particular milieu. The Moselle is over $500 \mathrm{~km}$ long with thousands of moorings along its banks. Finding a particular mooring may be difficult so a unique identifier such as outstretched fingers that can be easily recognized assists discovery. For the learner, noticing the unusual is helpful is a useful starting place. Even when learners look closely at this image they notice that there are more than five fingers on this hand.

\section{Multiple and complex reflections: Internal dialogue}

In the Adelaide Botanic Gardens there is a mirror, glass and water sculpture. I use this to discuss the complexity of internal dialogue. I look at this sculpture and see reflected in it multiple images. Reflection

26 Journal of Practice Teaching \& Learning 7(1) 2006-07, pp.22-38. ( 2007 Whiting \& Birch Ltd 
can be an internal dialogue with different parts of oneself, for example my professional self, my spirit or my role as a mother. This reflection can take place between multiple other parties, with these voices also incorporated into our internal dialogue.

Tsang (2005) referred to the importance of reflection as dialogue, arguing that reflection can take place internally and with others in small groups. He argued that if we see reflection as multiple voices and perspectives, the diversity of stakeholders and voices gives fuller expression to the core social work values of social justice, diversity and equality.

\section{Using cognitive skills}

Reflections are not necessarily clear or precise. A curved surface such as the Mall's Balls, another public sculpture in Adelaide, distorts the images of buildings around it. What we perceive is not necessarily accurate. The accuracy or the truth of our perceptions can be challenged. We must go behind the reflection to see what is really there. I tell my students that reflecting requires knowledge and demands the use of cognitive skills, including using powers of analysis, synthesis and evaluation so that we can develop hypotheses and increase our understanding of practice. Here I refer to Bloom's taxonomy or de Bono's hats. Bloom referred to the importance of knowledge, comprehension, application, analysis, synthesis and evaluation (Bloom 1984), whilst Edward de Bono (1985) had six hats that are used to think in particular ways. The white hat is about information and data; the yellow hat outlines the good points and optimistic views; the black hat allows us to comment negatively; the green hat provides for creative solutions; the red hat encourages feelings and emotions; and the blue hat fosters planning.

\section{Naming our taken-for-granted assumptions}

Noticing and naming is just the first part of the reflection process. Students need to go beyond this and understand what their observations mean, searching for the patterns and principles. It is only when this has been achieved that they can explore their taken-for-granted assumptions about institutions, structures and social work practice. I want them to 
confront and explain how broader social and cultural factors influence the way we think about the world. This fits with Fook's concept of critical reflection, a process of practice analysis where assumptions are identified and subject to examination using power is enacted in social structures (Fook, 1999).

As students are at the start of their first placement, I ask them to discuss their professional associations requirement that students should undertake 980 hours of practical learning before they can become qualified as a social worker. Why 980 hours rather than 950 hours or 1000 hours or even 2000 hours? Any reflection that challenges assumptions is best done with others. As Paolo Freire noted, acting alone is the best way to commit suicide (Shor, 1987, p.161). Others can assist us to break the cycle of our own thinking. We learn best when we are in conversations with our colleagues and though a community of practice.

\section{Accountability}

Lights on an airport runway at night are an important tool for pilots all over the world. The landing lights on the plane are reflected from various reflectors on the runway assisting the pilots to guide the plane to safety. Using reflection carefully and diligently is an expected part of the pilots' professional practice. One purpose of reflection is accountability, being able to account for our decisions and actions with clients or customers.

\section{Stories and reflection}

Reflections can also involve narratives and stories practitioners tell their students about their practice as a way of modeling their cognitive processes. These stories can be analysed in particular ways using various critical perspectives. As a young child, one of my favorite bedtime stories was Snow White, the Brothers Grimm published this story at the beginning of the $19^{\text {th }}$ century. It has since been revised by Disney pictures and subsequently enjoyed by my own children and many others. The story is about vanity, jealousy and power. Whilst with the wisdom of hindsight, it can be seen as a statement about the state below.

28 Journal of Practice Teaching \& Learning 7(1) 2006-07, pp.22-38. ( 2007 Whiting \& Birch Ltd 
The story allows us to go outside the private world of reflections, and understand the socio-cultural aspects of reflection and the way history shapes reflections.

\section{Reflection and problem solving}

During winter, as the snow was falling, a vain queen wished for a child that was as white as snow, with lips as red as blood and with hair the colour of ebony. When this child was born she was called Little Snow White. The queen believed that she was the most beautiful person in the land and each morning she stood in front of her mirror and asked herself:

Mirror, mirror, on the wall,

Who in this land is fairest of all?

And the mirror always said:

You, my queen, are fairest of all.

When the mirror responded, she knew that she was the most beautiful person in the world.

As Snow White grew up, her beauty surpassed that of the queen so that when the queen asked the mirror who was the fairest, the mirror said:

'You, my queen, are fair; it is true

But Little Snow White is still

A thousand times fairer than you.

From that point on, the queen was envious and set about disposing of Snow White using a range of deceptions. Throughout the story, the queen constantly uses the mirror to assist her to determine Snow White's whereabouts as well as giving her messages about her beauty - messages the queen does not want to hear. Here reflection refers to problem solving and facing the truth about oneself, as well as unwanted information.

29 Journal of Practice Teaching \& Learning 7(1) 2006-07, pp.22-38. ( 2007 Whiting \& Birch Ltd 


\section{Learning reflection}

Visual and verbal imagery can provoke learning but this has to be accompanied by student engagement in interactions and activities. This is done initially in three ways learning preparatory empathy, learning triggers for learning and associated learning activities and maintaining a sense of ignorance to motivate inquiry, discovery and critical analysis of practice.

\section{Learning reflection: Preparatory empathy}

Many educators wrongly assume that students come to placements with little or no relevant prior experience. In a metaphorical sense they are regarded as a blank slate. In the absence of a social work placement, is it possible to reflect on something where there has not been a prior experience? Reflection then is a process of using prior experiences to problem solve and to learn from these experiences. Whilst I assure students that reflection is best done on their practice, I also tell them that it can be done on their personal experiences and that of others.

The first stage of preparing for learning in the absence of professional experience is learning 'preparatory empathy', described in the social work literature by Shulman (1992). It is also summed up by the song 'Walk a Mile in my Shoes', written by Joe South and made famous when sung by Elvis Presley:

Walk a mile in my shoes

Walk a mile in my shoes

And before you abuse

Criticise and accuse

Walk a mile in my shoes

In undertaking this preparatory empathy, students come to understand that they need to have and exercise both intellectual and emotional empathy. The basis of reflection is understanding the feelings experienced by self and others. Reflection involves both thinking and emotions.

30 Journal of Practice Teaching \& Learning 7(1) 2006-07, pp.22-38. ( 2007 Whiting \& Birch Ltd 


\section{Learning reflection: Triggers}

In practice, something generally triggers reflection. That something can be a sense of discomfort, chaos, asymmetrical patterns, a critical incident or a messy situation. It can be a moment of surprise, worry, concern, an unexplained interaction or a time when values collide. I contrast the 'cold' and predictable learning of the university with the 'hot' learning that is present in the agency. Hot learning has immediacy and cannot be replicated. Once these triggers are identified students are encouraged to use critical incident analyses, process recordings, case studies, personal stories and dilemmas as the triggers for reflection. Whilst beginning students readily see the dramatic situations, with increasing experience students will become aware of the more mundane.

\section{Learning reflection: Maintaining an ignorance perspective}

One strategy for encouraging students to reflect is maintaining a sense of ignorance as a way of enabling and maintaining curiosity about practice. In higher education, students often believe they are expected to know the answers. This 'having the right answer on demand' prevents students from maintaining an open mind and exploring different areas. Encouraging ignorance provides students with a freedom to ask simple questions and seek the answers to these questions.

\section{Pedagogical frameworks underpinning reflection}

\section{The educator's responsibility}

In discussing the teaching of reflection, educators may be inclined to ignore their role as educator. In social work, educators have a responsibility to ensure that students not only understand reflection but see this in the context of the profession, ethics, values, knowledge and skills. Throughout this process, I model my thinking and experiences as a learner and practitioner as a way of conveying alternative ways of looking at the world. This cognitive modeling is also referred to as a 'cognitive apprenticeship', which places emphasis on teaching learners

31 Journal of Practice Teaching \& Learning 7(1) 2006-07, pp.22-38. ( 2007 Whiting \& Birch Ltd 
different ways of thinking and understanding practice, reflection and learning (Brown, Collins and Duguid 1989).

In social work, scholars refer to the 'theory' of the classroom and the 'practice knowledge' in the agency, and often regard them as separate entities. Historically, social work educators have referred to making the links between theory and practice as a particular educational goal, although many students and practitioners have challenged the usefulness of this strategy in the cut and thrust of social work practice. Classroom knowledge has greater status, whereas practice knowledge is low in status. With Schön's work $(1983,1987)$, greater emphasis was placed on the knowledge embedded in, and arising from actual practice. This is the knowledge social workers use every day without thinking it is important.

Practice is based on theoretical knowledge, technical knowledge, procedural knowledge and importantly the knowledge that arises from practice. Practitioners have their tacit theories about how best to work with and assist clients, groups and communities. Practitioners construct and reconstruct these theories, which they pass on orally to other generations of social workers as 'practice knowledge'. As practitioners are working in complex and murky situations, reflective practice allows them to access their practice wisdom and make thoughtful solutions to practice matters. Educators need to allow access to these messy situations safely and with accountability to agency, client, practice teacher and their own professional development.

Some social work academics often provide frameworks enabling students to reflect on practice. Although it maybe useful for some students I am reluctant to provide a sequenced or step-like process. This is in agreement with Boud and Knights (1996), and Taylor (1996) who point out that educators need to create a context for reflection that creates space for problem solving, developing learning activities and supporting people who are able to facilitate this process.

\section{Understanding students}

Before turning attention to those authors who specifically address reflection, it is necessary to consider the students who are expected to learn the art of reflection. For classroom and practice teachers, this is a very challenging time. Reflection is not something students learn or come to

32 Journal of Practice Teaching \& Learning 7(1) 2006-07, pp.22-38. ( 2007 Whiting \& Birch Ltd 
understand because it is explained using interesting power points. They want the right answers immediately and the correct way of doing things and expect their teachers to provide this. They are willing to work hard, as they see this as the way to achieve success. As our young students may not have the intellectual maturity and tolerance of ambiguity of many practitioners it is important for both teachers and students to understand that learning reflection is a developmental process that cannot be learnt (or taught) the way one might prepare for a statistics test.

Throughout the course of their university studies, young adults develop intellectual and cognitive maturity. Several studies have been done on young men showing their intellectual development. Perry (1970) developed a model of cognitive development, based on a study of Harvard male graduates. This model has nine distinct positions arranged in a hierarchy with simple thinking patterns and a dualistic (right and wrong) approach to level nine that is more relativistic. Perry was particularly interested in the transition points between these levels, as this is where the ambiguity and self-questioning about learning and practice take place.

Perry's work was criticised because the subjects were male. As a balance, Belenky, Clinchy, Goldberger and Tarule (1986) specifically investigated women's ways of knowing. They also developed a hierarchical categorisation beginning with silence (where women feel mindless and voiceless) and ending with a position where the women are able to construct and create knowledge for themselves.

A more recent theoretical development is King and Kitchener's (1994) reflective judgement model. Students do not acquire the skills of reflective practice as fully formed skills to be used in practice. Rather, reflective skills develop over time, beginning in childhood. King and Kitchener's model is also sequential and it is not until students reach the last two stages that the capacity for reflective thinking is achieved. There are many similarities to the Perry model, for example in the early stages people are pre-reflective and gain knowledge from authority figures. In the middle stages young adults are subjective and define knowledge in terms of uncertainty. In the latter stages of development, young adults realise that in order to solve difficult and complex problems, they may have to construct their own solutions.

What we can conclude from these studies is that learning reflective thinking is a developmental process and that students may not have sophisticated ways of thinking until they are in their final years. 


\section{Pedagogical frameworks}

We are indebted to Dewey, whose writings about reflection almost 100 years ago have impact on more recent writers. Dewey regarded reflection as a process of thinking and learning how to think, or 'the need for training thought' (Dewey 1933). Thinking is not necessarily an easy process because it means overcoming our inertia and laziness, and not accepting any information or observation at face value.

What we see should be a puzzle that creates unrest and disturbance, not unlike the ripples in a reflection in the water. Reflection is an uncomfortable and painful process, as learners suspend judgement and remain doubtful whilst they continue with a problem solving process. Whilst holding judgement, reflection on issues means that students will create a space between their judgements and reactions so that they hear ideas and people in different ways. Suspending judgement for long periods whilst students continue with the searching process can be challenging and support is needed at this stage. The process of reflection is emotionally difficult for beginning students who have dualistic thinking and want right answers from authority figures immediately.

Dewey (1933) outlined a process beginning with a state where a difficulty is felt and the mind plays with lots of possible solutions. This state includes thinking about means and ends. In the next stage, the problem is framed and elaborated as a problem to be solved. In stage three, a range of hypotheses is suggested as a way to guide observations and collection of material. In stage four, reasoning about the problem is evident. The final stage of reflective practice involves testing by overt or imaginative action. Dewey's model appears in various forms and in subsequent reflective models, including Boud et al. (1985) and Kolb (1984), and in the problem solving process elaborated in the early social work text by Perlman (1971).

Many other writers have built on Dewey's work. They have described how we learn from experience and have used the concept of reflection. Kolb (1984) was one of the significant early writers. He wrote about his learning cycle and significantly influenced the intellectual thinking in field education (Bogo and Vayda, 1998). In his model, Kolb referred to a willingness to engage in new experiences (concrete experience); observational and reflective experiences so that these experiences can be viewed from a variety of perspectives (reflective observation). Also analytical and evaluative abilities so that these experiences can deepen

34 Journal of Practice Teaching \& Learning 7(1) 2006-07, pp.22-38. ( 2007 Whiting \& Birch Ltd 
our understanding of experiences (abstract conceptualization); and the implementation of learning in practice (active experimentation). Kolb aligned his learning cycle to particular learning styles. This model has been used by Bogo and Vayda (1998) to explain the process of learning in field education, with the exception that the circle is represented as a spiral that continues on with the initial process.

Kolb's work has been criticised for not giving more attention to elaboration of reflection in the discussion of the dimensions of his circle. Boud at al. (1985) developed this aspect further. Other criticisms specifically relate to the learning styles associated with each dimension, as there are other ways of learning besides experientially. Kolb's model does not take account of situated learning or its operation in different cultural conditions. Of major concern is his elaboration of the stages or steps in the learning process, as it is not possible to have a set sequence for reflection - all these processes overlapping or occurring at once. The value of Kolb's model is its value in teaching practice.

Boud, Keogh and Walker $(1985,1996)$ developed a model of reflective practice that takes account of three stages, including returning to and replaying the experiences, attending to the feelings associated with and provoked by the experience, and reevaluating the experience. The critical part of this reflective model is identifying feelings associated with the experience. It suggests focusing on positive feelings about the experiences and removing negative feelings that obstruct learning.

More recently, Boud and Walker (1990) have revised this model to incorporate Schön's (1983) concepts of reflection-in-action, that is reflection and experience are interacting partners. Their revised model is complicated, learning cannot be separated from the milieu in which the learners are situated, and their prior personal experience as well as their intent in preparing for the experience is critical. The learner becomes aware of their milieu by noticing and becoming aware of people, interactions, values, behaviours and skills, and uses this as the basis for reflection. The second part of reflection involves intervention in a situation. This may be working with an individual to initiate a change strategy, or a more minor intervention such as asking questions or clarifying matters. The reflective process involves returning to the experience, attending to feelings and re-evaluating the experience.

Donald Schön influenced by Dewey's work, placed reflection at the heart of professional practice, which he argued, is messy and not easily resolved. He criticised technical rationality as the dominant profes- 
sional paradigm and proposed reflection as an alternative approach (Schön 1995). Schön referred to the importance of reflection-in-action, which is akin to thinking on our feet, and reflection-on-action, which is a thinking that takes place after the experience. Reflection-in-action occurs in practice, it is the hot learning, the critical incidents, the surprises that happen moment by moment, and as it occurs we incorporate it into our practice. Reflection-on-action is done after the experience as practitioners debrief, talk to colleagues, write journals or have supervision. This reflection allows practitioners to reflect on their feelings, intentions, observations and interventions. Through exposure to many messy situations, practitioners build a library or repertoire of experiences and routines for resolving practice problems. They then use their repertoire of experiences to make sense of unique situations. Reflection allows us to give voice to this repertoire of experiences and draw on them in the future.

\section{Conclusion}

As this paper illustrates, reflection is a complex process that can open the door to effective teaching and learning of social work practice. Reflection, in conjunction with social work placements, provides a key to bridging theory and practice.

Awareness of your own and your students' attitudes and experiences is imperative in teaching, learning and practicing practice. This awareness enables reflection using the tools of noticing, carrying on an internal dialogue, stretching your cognitive skills to ensure we are not tricked and recognising and naming our taken-for-granted assumptions, and problem solving.

\section{References}

Belenky, M.E., Clinchy, B.M., Goldberger, N., and Yarule, J. M. (1986) Women's Ways of Knowing: The development of self, voice, and mind. New York: Basic Books

Bloom, B.S. (ed.) (1984) Taxonomy of Educational Objectives. New York: Longman.

36 Journal of Practice Teaching \& Learning 7(1) 2006-07, pp.22-38. (C) 2007 Whiting \& Birch Ltd 
Bogo, M., and Vayda, E. (1998) The Practice of Field Instruction in Social Work: Theory and process. (2nd ed.) Toronto: University of Toronto

Boud, D., and Knights, S. (1996). 'Course design for reflective practice', in N. Gould and I. Taylor, Reflective learning for social work. Arena, Aldershot

Boud, D., and Walker, D. (1990) Making the most of experience. Studies in Continuing Education, 12, 2, 61-80

Boud, D., Keogh, R., and Walker, D. (Eds.) (1985) Reflection: Turning experience into learning. New York: Kogan Page

Boud, D., Keogh, R., and Walker, D. (1996) Promoting reflection in learning: A model. in R. Edwards, A. Hanson, and P. Raggatt (Eds.), Boundaries of Adult Learning. London: Routledge

Brown, J.S., Collins, A., and Duguid, P. (1989) 'Situated cognition and the culture of learning. Educational Researcher, 18, 1, 32-42

de Bono, E. (1985) Six Thinking Hats. Boston: Little, Brown

Dewey, J. (1933) How we Think: A restatement of the relation of reflective thinking on the educative practice. Lexington, MA: Heath

Fook, J. (1999) Critical reflectivity in education and practice. in B. Pease and J. Fook (Eds.) Transforming Social Work Practice: Postmodern critical perspectives. Sydney: Allen \& Unwin, pp.195-208

Graham, G., and Megarry, B. (2005) The social care work portfolio: An aid to integrated learning and reflection in social care training. Social Work Education, 24, 7, 769-780

Goldstein, H. (2001) Experiential Learning: A foundation for social work education and practice. Washington, DC: CSWE Press

Gould, N. (1996) Using imagery in reflective learning. in N. Gould and I. Taylor, Reflective Learning for Social Work. Aldershot: Arena

Ixer, G. (1999) There's no such thing as reflection. British Journal of Social Work, 29, 513-527.

King, P.M., and Kitchener, K.S. (1994). The Development of Reflective Judgment in Adolescence and Adulthood. San Francisco: Jossey Bass

Kolb, D.A. (1984) Experiential Learning: Experience as the source of learning and development. New Jersey: Prentice Hall

Perlman, H.H. (1971) Social Casework: A problem solving process. Chicago: University of Chicago Press

Perry, W.G. (1970) Forms of Intellectual and Ethical Development in the College Years. Austin, TX: Holt, Reinhart \& Winston

Rogers, C. R. (1969). Freedom to Learn: A View of what education might become. Columbus, OH: C. E. Merrill

37 Journal of Practice Teaching \& Learning 7 (1) 2006-07, pp.22-38. @ 2007 Whiting \& Birch Ltd 
Schön, D. (1983) The Reflective Practitioner: How professionals think in action. New York: Basic Books

Schön, D. (1987) Educating the Reflective Practitioner. New York: Jossey Bass Schön, D. (1995) Knowing-in-action: The new scholarship requires a new epistemology. Change, November/December, pp.27-34.

Shor, I. (Ed.) (1987) Freire for the Classroom: A sourcebook for liberatory teaching. Portsmouth, NH: Boynton/Cook

Shulman, L. (1992) The Skills of Helping: Individuals, families and groups. (3rd edn) Itasca, IL: F.E. Peacock

Taylor, I. (1996) Facilitating reflective learning. in N. Gould and I. Taylor Reflective learning for social work. Aldershot: Arena

Tsang, N. M. (2005). 'Reflection as Dialogue', British Journal of Social Work. Advance access, published online September 5, 2005. Available at: http:// bjsw.oxfordjournals.org/cgi/content/abstract/bch304v1 